\title{
GASIFICATION STUDY OF SARAWAK COALS
}

\author{
Nor Fadzilah Othman* \\ College of Graduate Studies, Universiti Tenaga Nasional (UNITEN), \\ KM 7, Jalan Kajang-Puchong, 43009 Kajang, Selangor Malaysia
}

Mohd Hariffin Bosrooh

Mechanical Department, School of Engineering, Universiti Tenaga Nasional (UNITEN),

KM 7, Jalan Kajang-Puchong, 43009 Kajang, Selangor Malaysia

Received 20 December 2005

\begin{abstract}
Thermogravimetry (TG) has been applied in a preliminary investigation, to the gasification of two low rank Sarawak coals. The coal samples, about $10 \mathrm{mg}$ were investigated within the temperature range $30-900^{\circ} \mathrm{C}$ at different heating rate of 10,20 and $30^{\circ} \mathrm{C} \mathrm{min}{ }^{-1}$, under a synthetic air atmosphere for the gasification study. The kinetic parameters were determined using Arrhenius type reaction model assuming a first-order reaction. The reactivity, $R_{T}$ values are fitted with Arrhenius equation at $\mathrm{r}^{2}=0.83-0.98$ for MP coal, while the $R_{T}$ values for MB coal are fitted with the Arrhenius equation at $\mathrm{r}^{2}=0.99$. The activation energy, $E_{A}$ for MP coal are in the range of $3.7-$ $4.7 \mathrm{~kJ} \mathrm{~mol}^{-1}$ and for MB coal are $7.6-25.6 \mathrm{~kJ} \mathrm{~mol}^{-1}$ at 3 different heating rates.
\end{abstract}

Keywords: gasification, Sarawak coals, thermogravimetric, reactivity, Arrhenius equation

\section{INTRODUCTION}

Thermogravimetry (TG) is widely applied to determine reaction rate processes of coals [1]. This method involves a continuous measurement of the change in mass or rate of mass loss (differential thermogravimetric, DTG) of a sample with temperature or time. Kinetic parameters, such as activation energy and order of reaction, can be derived from these types of data.

Many experimental techniques have been employed in the studies of reaction mechanism and kinetics for carbon gasification reaction such as temperature-programmed desorption (TPD), thermogravimetric analysis (TG), transient kinetics (TK), transmission electron microscopy (TEM) and scanning tunneling microscopy (SEM) [2]. Among them, TG is the most popular and widely used method. The non-isothermal TG with a linear temperature growth is a method frequently used to characterize materials from their thermal behavior standpoint. In addition, it enables to determine apparent kinetic parameters of heterogeneous reactions, such as the reaction order, $\mathrm{n}$, the apparent activation energy, $\mathrm{E}$ and the frequency factor, $\mathrm{A}$. The present calculation methods are either based on a single TG curve or require several TG curves measured at various heating rates [2].

\footnotetext{
* Corresponding author e-mail: norfadzilahothman@yahoo.com
} 
In general, a total gasification process can be broadly separated into two main reaction stages: pyrolysis and char gasification [3]. In the present study, the kinetics of the gasification processes have been investigated, using a TG apparatus under non-isothermal conditions, for two Malaysian coals in relation to the final temperature. The aim of this investigation is to study the behaviour of the Malaysian coals in $\mathrm{O}_{2}$ (air) gasification reaction. Prior to these reactions, the coals were characterized according to the apparent activation energy and Arrhenius constant. This paper will discuss the gasification study of Sarawak coals using TG and DTG data, as well as the kinetic parameters.

\section{MATERIALS AND EXPERIMENTAL METHOD}

\subsection{Types of coals used}

Two coals have been chosen from the Sarawak coalfield, which are Merit Pila (MP) and Mukah Balingian (MB) coals. The calorific value and proximate analysis of the samples are shown in Table 1.

Table 1: Properties of Sarawak coals.

\begin{tabular}{lccccc}
\hline \multirow{2}{*}{ Coals } & \multirow{2}{*}{$\begin{array}{c}\text { Calorific value } \\
\text { (Kcal/kg, HHV) }\end{array}$} & Moisture & $\begin{array}{c}\text { Volatile } \\
\text { matter }\end{array}$ & $\begin{array}{c}\text { Fixed } \\
\text { carbon }\end{array}$ & Ash \\
\cline { 3 - 6 } Merit Pila (MP) & 5800 & 15 & 43 & 36 & 6 \\
Mukah Balingian (MB) & 5030 & 15 & 38 & 39 & 8 \\
\hline
\end{tabular}

\subsection{Thermogravimetric analysis}

The tests were performed in a Seiko TG/DTA 220U Thermogravimetry system with the temperature programming software of the furnace. The purge gas was air for the gasification tests, supplied at a constant rate of $300 \mathrm{~mL} \mathrm{~min}^{-1}$. The sample weight loss (TG signal) and rate of weight loss (DTG signal) as functions of time or temperature were recorded continuously under dynamic conditions in the range $30-900^{\circ} \mathrm{C}$. In this investigation, TG data were used to determine the effect of different coal samples on the constant heating rate.

Gasification was carried out non-isothermally using a sample, about $10 \mathrm{mg}$, place in the platinum crucible, which was then put on the sample pan hanging down in the reaction tube, in which the atmosphere could be controlled. The furnace tube was raised to close the system, and the start button depressed. The pre-programmed control-unit regulates all the automatic functions of the recorder (e.g. the continuous change in the mass of the sample is measured), as well as the temperature programming of the furnace. Finally, and after the furnace temperature had achieved its set value, the sample was allowed to cool to normal room-temperature.

\section{RESULTS AND DISCUSSION}

\subsection{Gasification}

Figures 1 and 2 display the weight loss and DTG curves for the MP and MB coals at different 
heating rates. Again, it is clear that the rate of conversion of the organic content is directly related to the gasification temperature: the higher the temperature, the greater the weight loss. Also, the two coals exhibit qualitatively the same patterns of thermal degradation when the gasification temperature was raised over the studied range. The gasification process for MP completed earlier at about 450,480 and $500^{\circ} \mathrm{C}$ compared with $\mathrm{MB}$ at about 505,530 and $550^{\circ} \mathrm{C}$ at heating rates of 10,20 and $30{ }^{\circ} \mathrm{C} \mathrm{min}$. . MP coal sample exhibits 96,97 and $98 \%$ of its total weight loss compared with the $\mathrm{MB}$ coal (i.e. more than $\mathrm{MB}$ coal by about 13,6 and $8 \%$ at heating rates of 10,20 and $30{ }^{\circ} \mathrm{C} \mathrm{min}^{-1}$ ), which exhibits the total weight loss of 94,91 and $89 \%$ at heating rates of 10,20 and $30{ }^{\circ} \mathrm{C} \mathrm{min}$.
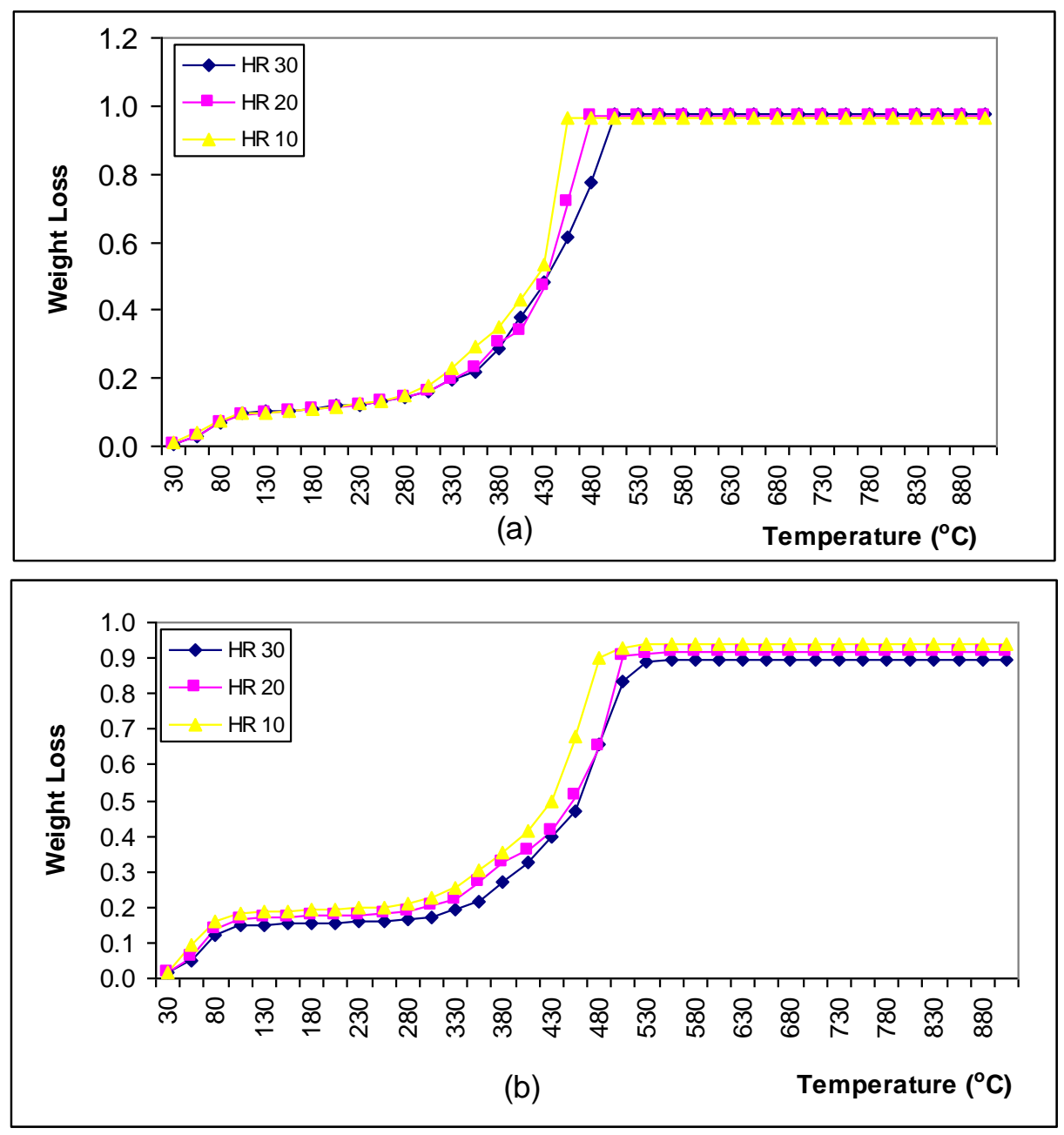

Fig. 1: Gasification behaviour of (a) MP and (b) MB coals at different heating rates (HR).

In the presence of air, coal decomposition was much more rapid, as expected. Because of the high rate of the $\mathrm{C}+\mathrm{O}_{2}$ reaction (sharper DTG peaks) the main stages of decomposition, i.e., zones II and III, merged (Fig. 2) [4]. The reaction was completed in a much shorter time. In fact the coal was reduced to a white ash upon completion of the gasification process at about 450 $550^{\circ} \mathrm{C}$ for the 3 different heating rates.

The shift in the DTG peak is a measure of reactivity value. The reactivity values [5] were 
calculated according to the following relationship:

$$
R_{T} \frac{1}{W_{o}} \cdot \frac{d_{w}}{d_{t}}
$$

where $W_{o}$ is the starting weight of the coal on a daf basis and $\mathrm{d} w / \mathrm{d} t$ is the maximum from the DTG curve (are illustrated in Figs. 1 and 2). The reactivity values for gasification of MP and MB in air are shown in Table 2. The $R_{T}$ values for MP are almost consistent at 3 different heating rates $\left(0.32-0.34 \mathrm{~min}^{-1}\right)$, since the temperature at which the maximum rate of decomposition occurred for the 3 different heating rates are almost the same $\left(\sim 380^{\circ} \mathrm{C}\right)$. While MB coal had shown $R_{T}$ values of $0.26-0.34 \mathrm{~min}^{-1}\left(430-440^{\circ} \mathrm{C}\right)$. Since, the $R_{T}$ values for MP and MB coals are almost near to each other, most probably they are in the similar coal rank [5].
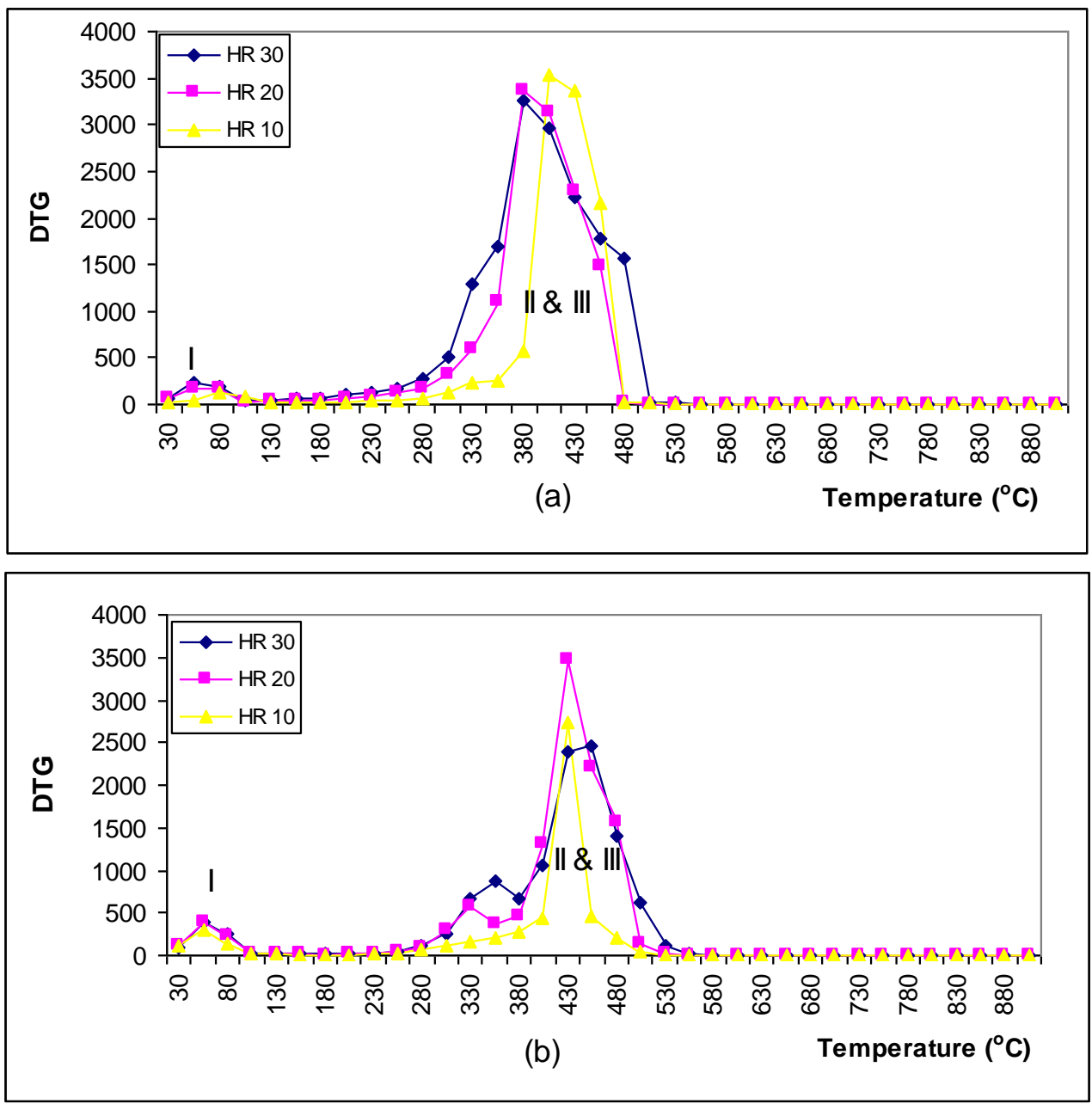

Fig. 2: DTG of the (a) MP and (b) MB coals at different heating rates (HR), in relation to the gasification temperature.

The $R_{T}$ values are fitted with Arrhenius equation at $\mathrm{r}^{2}=0.83-0.98$ for MP coal, while the $R_{T}$ values for MB coal are fitted with the Arrhenius equation at $\mathrm{r}^{2}=0.99$. The activation energy, $E_{A}$ 
which is required to break the strong chemical-bonds and completing the carbon-dioxide/char reaction for MP coal are 4.75, 5.33 and $3.76 \mathrm{~kJ} \mathrm{~mol}^{-1}$ and $E_{A}$ values for $\mathrm{MB}$ coal are 25.66, 7.61 and $13.22 \mathrm{~kJ} \mathrm{~mol}^{-1}$ at 3 different heating rates. Overall, $\mathrm{MB}$ coal has higher $E_{\mathrm{A}}$ value, compared to MP coal at 3 different heating rates. The gasification kinetics parameters were calculated within the temperature range of $653-803 \mathrm{~K}$ for MP and MB coals. The higher $E_{A}$ values are not related to a lower $R_{T}$ values.

The $E_{A}$ values for MP coal and MB coal in the gasification process are much more lower compared with the $E_{A}$ value from previous studies using different types of coal, with $E_{A}$ values between $100-300 \mathrm{~kJ} \mathrm{~mol}^{-1}[5-7]$.

Table 2: Reactivities of MP and MB coals in air.

\begin{tabular}{lcccc}
\hline Coal type & $\begin{array}{c}\text { Sample's rate of } \\
\text { temperature rise } \\
\left(\mathbf{C}^{\mathbf{0}} \mathbf{~ m i n}^{-\mathbf{1}}\right)\end{array}$ & $\begin{array}{c}\text { Temperature at which } \\
\text { maximum rate-of- } \\
\left.\text { decomposition occurs } \mathbf{~}^{\mathbf{0}} \mathbf{C}\right)\end{array}$ & $\begin{array}{c}\mathbf{R}_{\mathbf{T}} \\
\left(\mathbf{m g ~ m}^{-1} \mathbf{h}^{\mathbf{- 1}}\right)\end{array}$ & $\begin{array}{c}\mathbf{E}_{\mathbf{A}} \\
\left(\mathbf{k J} \mathbf{~ m o l}^{-\mathbf{1}}\right)\end{array}$ \\
\hline \multirow{3}{*}{ MP } & 10 & 380 & 20.68 & 4.75 \\
& 20 & 380 & 19.79 & 5.33 \\
& 30 & 380 & 19.00 & 3.76 \\
MB & 10 & 430 & 15.85 & 25.66 \\
& 20 & 430 & 20.52 & 7.61 \\
& 30 & 440 & 14.89 & 13.22 \\
\hline
\end{tabular}

\section{CONCLUSIONS}

Using air (gasification) in the TG system incurred a slight increase in the weight loss for the MP and MB coals. The determination of the kinetics parameters such as $R_{T}$ and $E_{\mathrm{A}}$ are fitted with the Arrhenius equation, for the considered temperature range.

It is known that the coal $R_{T}$ values will increase with the decreasing rank of the coal. However, the $R_{T}$ values for MP and MB coal are within the same range in gasification process using different heating rates, which indicates that the MP coal approximately, has a similar reactivity with MB coal in air and most probably the MP coal is from the same coal rank.

Since, the kinetics study for Malaysian coals has never been conducted earlier, this study hopefully, will be the baseline for the future works. Further studies can be conducted using other types of Malaysian coals and also other methods of kinetic parameters determination.

\section{ACKNOWLEDGEMENT}

Authors acknowledge the financial support from Seeding Fund, TNB Research Sdn Bhd.

\section{REFERENCES}

1. Kneller, W.A. (1986), Physicochemical characterization of coal and coal reactivity. A review. Thermochimica Acta, 108, pp. 357-388.

2. Wang, S. et al. (2005), Kinetic studies of graphon and coal-char reaction with $\mathrm{NO}$ and O2: direct non-linear regression from TG curves. Fuel Processing Technology, 86, pp. 651-660. 
3. Pan, Y.G., et al. (1996), Pyrolysis of blends of biomass with poor coals. Fuel, Vol. 75, No. 4, pp. 412-418.

4. Serageldin, M.A. and Pan, W-P. (1984), Coal analysis using thermogravimetry. Thermochimica Acta, 76, pp. 146-160.

5. Fernandez-Morales, I., et al. (1985), Study of heat-treated Spanish lignites. Characteristics and behaviour in $\mathrm{CO} 2$ and $\mathrm{O} 2$ gasification reactions. Fuel, 64, pp. 666-673.

6. Liu, X. et al. (2001), Analysis of pyrolysis and gasification reactions of hydrothermally and supercritically upgraded low-rank coal by using a new distributed activation energy model. Fuel Processing Technology, 69, pp. 1-12.

7. Ye, D.P. et al. (1998), Gasification of a South Australian low-rank coal with carbon dioxide and steam: kinetics and reactivity studies. Fuel, 77, pp. 1209-1219. 